\title{
Application of painting principle in garden planning and design Chang SU
}

\author{
Shenyang Agricultural University, School of Forestry, Shenyang, Liaoning, China \\ zhaoyan024@126.com
}

Keywords: Painting principle; Garden planning and design; Application

\begin{abstract}
The principle of painting art has penetrated into all aspects of landscape design, whether in the surface of two-dimensional space, the body of three-dimensional space, the time of four-dimensional space, the meaning of five-dimensional space, the meaning of the shape, or in the color of the mix and harmony. The artistic principle of painting permeates into the garden design and at the same time, it push the beauty of gardens to the highest level.
\end{abstract}

\section{Introduction}

Garden art and painting art belong to the category of plastic arts in aesthetics; they are the combination of visual art, space art and static art. Garden design is a natural tridimensional picture scroll, is in the three-dimensional form of three-step space to show the physical nature of the scene, but the painting has compressed the three-step space to become a plane; Landscape design combines the beauty of nature, the beauty of life, the beauty of painting, the beauty of architecture, the beauty of literature and so on. The beauty of garden embodies the three-dimensional painting, solidified music and silent language. Among them, the infiltration of the artistic principle of painting in the garden design pushes the beauty of garden to the highest level.

\section{Application of point, line and surface}

In painting, points form the curves, straight lines, slant lines, vertical lines, snake lines and so on through rhythmic movement, and the lines form different surfaces through various arrangements. The accumulation of points, lines, and planes forms a perfect picture. The point we are talking about here is not only two simple modeling elements, more importantly, it represents a theme, with characteristics of points, focus, and accumulation. Where the focus of a painting is, where is the theme of the painting.(1)Similarly, each garden design also has its theme and the main scene, the topic is formed by scattered points, such as the building, the platform, the pavilion, the pavilion and so on. Lines of different natures and forms, such as soft, plump, vital curves, round lines, soothing, flowing serpentine lines, wave lines, heavy, straight vertical lines, and unrestrained and unstable diagonal lines, are used in painting. Draw clouds and draw water to the best of its ability. It not only shows the shape and spirit of the image, but also has the value of formal beauty. In the garden design, existence of line is everywhere, such as the road, the green belt, the flower bed and the promenade design. Through the different form line, it displays the different degree the dynamic feeling, namely the line movement lasting appeal, the rhythm, achieves is firm and soft with each other, has the quality to have the rhyme; In this way, can have a strong artistic charm. The point and the line have some local individuality characteristic, the surface displays for the wholeness and has represented the general character. Only through the combination of point, line and surface can we deal with the relationship between individuality and generality, between part and whole. In painting, a painter often looks at the wholeness, not only a part of it, of an object with his eyes half-closed, that is to say, no matter what line he uses to depict the focal point, the emphasis must be unified in the same background and in the same tone. The same theme atmosphere is forming a unified face. Garden design also follows the fundamental principles of painting art and plastic arts. In the configuration of plant, the shape of trees, color, lines, dry texture and proportion of leaves, all of them have a certain degree of difference and change, showing the delicate and varied points. However, it is necessary to maintain a certain degree of similarity between them so as to bring 
about a sense of unity. Such as neatly arranged, equal spacing of street trees, by one or two unified tree species throughout the orderly, make people's scattered line of sight into a unified whole, a variety of flowers interspersed only local embellishment. Whether trees, pools, lawns, or rockeries, fountains, sculptures and other buildings formed the "surface", are the use of points and lines together constitute a reasonable sense of the modern landscape as a whole.(2)

\section{Harmony of colors}

The profusion of color is the beauty that nature has bestowed on human beings. The interweaving of color and light permeates every corner of painting and landscape design. The Impressionism appeared in the 19th century French art history is the representative of the color revolution which gives priority to the color impression. From Manet's "lunch on the Grass" to Monet's "impression of the Sunrise", as well as Van Gogh, Cezanne's works and so on, all of them are the use of color brushwork, the language of painting and the rules of painting to create a picture of color and color clash with each other. It has achieved the visual transformation, forms one kind of light and the shadow harmony. In ancient China, the color of traditional Chinese painting was called "Danqing", that is to say, it was painted with the method of flat painting and dizziness. Even the traditional ink painting, also has its unique color space. The "painting things micro "from Tang Dai in the Qing Dynasty, said: "there are six colors of ink. But the black and white not to distinguish is does not have the Yin and Yang, brightness and shade; dry and wet does not prepare, is does not have the verdant Xiurun; the thick and weak does not distinguish is not the concave and convex near far. Ink, there are "dry, wet, thick, light, black, white" six colors, not to mention the colorful nature of the landscape?

In the garden design, the landscape is based on plant landscape, architecture as a supplement, so in the plant configuration, color collocation should be considered with the time, season and change; we should be careful of the flower color, floral phase and flowering period of the plant. In the whole composition, the color must have a main tone, master the cold tone: blue, purple, gray to give people a quiet; warm tone: red, yellow, orange, brown to give people a warm feeling of this law, so that it runs through the scenic spots. Then we use pavilions, platform, paths and curved bridges in the gardens as embellishments in the design, accompanied by scales and waves of light mapped from the surface of the water, and floating clouds flying in the sky, forming a charm that is also real and illusory, and also real and empty, which contrasts with the physical landscape each other. In this way, the landscape of the whole garden is full of vigor and vitality, and has a kind of aesthetic feeling as a whole. No matter the fresh feeling of verdant or "a little red" in ten thousand green bushes, it shows that the harmony and application of color has become one of the main contents that cannot be ignored in the garden design.(3)

\section{General laws and rules of composition}

After painstaking exploration, the painter painted the natural landscape as a beautiful picture. Landscape designers transform the natural environment into the realm of beauty through ingenious organization, arrangements. No matter what kind of mood they want to create, the first thing to consider is composition. The main rules and principles of composition are as follows:

1. Choice. Gu Kaizhi, a painter of the Eastern Jin Dynasty, attached great importance to the "setting up of the old position" of painting and demanded "close to the essence of thinking" and "excellent judgment". Instead of seeing what he saw, he asked the painter to make some choices and carry out the "wonderful cutting" according to the need of the "cloth situation". Garden planning and design, is not a simple stacking of scenery, and it gives people a burdensome feeling if put a variety of flowers and plants in the same garden . On the contrary, repeated consistency, approximation, visitors will produce a sense of monotony, fatigue. This requires us to have the choice of scenery, "choose in a smart way ", that is, the so-called "touching the horizontal inclined 10 million, only three or two appreciation heart."

2. Guest and host. A painting should have a "main point", also known as the eye, the main point 
may be very small, but it is particularly eye-catching, thus highlighting the theme of the painting. If you have a master without an object, you will be lonely; if you have a guest without a master, you will be dissolute. Landscape design is also the same, many scenic spots, one of which must be the main scene, the other are subordinate, play a role as a foil to the main scene. Usually, the natural garden, the main landscape is often arranged on the center of gravity of nature; regular garden, the main landscape often occupies the geometric center; mixed garden, the main landscape is often at the intersection of the axis. All kinds of gardens give prominence to the main scenery, and they are arranged in different ways. In addition, the orientation of the building, the posture of the rock, the crown shape of the trees and so on are all restricted by the main scene, which plays the role of setting off the main scene. Only in this way can we create a clear and orderly landscape system.

3. Deficiency and reality, echo and density. Rocks, tree houses, clouds and water, figures and other images, are reflected in the screen should be taken to contrast the actual situation, echo the handover, the density of the method, in order to show the overall mood and charm. This technique of expression is widely used in garden space design. People often separate the two related spaces with open forest, corridor, leakage window, scaffolding and so on; separate two unrelated spaces with dense forests, buildings, water, and so on. Through scientific and reasonable arrangement, the separators in the spaced scenes echo with the scenery in the gardens from a distance, forming a solid space with emptiness and reality, with sceneries in sparse places and rhymes in dense places. Make the visitor swim after have a kind of full house scenery, lasting appeal infinite feeling.

4. Hide and reveal. Chinese painting is important in implicature. If everything is revealed, there will not be much interest in it. This depends on whether you can "hide", hidden well, so that "no scenery seems to have scenery," cannot see the meaning of the shape can be expressed, "so that the viewer has a rich imagination. Such as landscape painting, often borrow clouds and smoke, hidden to the mountain streams, water, many scenery, so that a person feel endless rivers and mountains, meteorology. As a result, limited into infinite, rich picture. So Guo Xi said: "if the mountains want to look high, they can't be seen when they are exposed. But they look high when the clouds are halfway up the mountain." Tibet and dew are dialectical unity, hiding is also for the sake of dew. All forms of hidden dew are intended to convey the subject more implicitly, leaving room for imagination. Chinese garden design is equally good at implicature. Some scenic spots do not reach the designated location. It doesn't really come out. The commonly used method is to set up a scene to block the line of sight, so that people have a sense of "there is no way out of doubt", and reach the state of "turning the corner but having a village." The skillful use of Tibetan and dew improves the artistic effect of paintings and scenic spots.

5. Opening and closing. Pay attention to the composition of the beginning and end of the painting. A painting from where to start, how to undertake echo, how to gather together, all of them need to have the overall situation of the arrangements, strict organization. Only the clear opening and closing, gathering and dispersing properly can show the theme of the idea that to be expressed. Landscape planning and layout, it also emphasizes the starting and closing, the opening and closing, in order to calculate a complete spatial composition. For example, each scenic spot in the garden has an opening and closing relationship, highlighting one of the small themes. Painting composition, a large composition can have several open and close, garden design, according to the content of the different attractions can have multiple open and close contains them. In addition, in the space processing, the open space and the locked space may form the contrast, the space has the opening and closing, makes up mutually, forms the open or the deep boundary, increased the spatial contrast feeling and the sense of levels, has played the attractive effect.(4)

\section{Application of Perspective principle}

The garden art and the drawing art belong to the space art type. Space includes two elements: one is color space; the other is body space, which refers to the basic shape, volume and position of objects in space, the relationship between objects before and after, the distance between objects, and the perspective relationship between objects. The painter correctly displays this kind of spatial relations on the plane, causes them to have the stereoscopic feeling and the far and near spatial sense method 
called the perspective method. (5) The garden is also like a landscape painting. When we design a garden , we must pay attention to the rich levels of composition and rendering each other, and deal with the relationship between the foreground, the middle scene and the prospect. The foreground depicts meticulously and the extension of the prospect vast space is to highlight and foil the service of the middle scene, the middle scene is the main body of viewing. According to the surrounding environment, topography and scale, the elements such as water, garden sketch, road and plants are reasonably combined to create a harmonious garden environment, forming a three-dimensional garden space art.

Wang Bomin, a theorist of contemporary Chinese painting, summed up the treatment of perspective in Chinese painting as "seven views method", that is, step by step, face-view, single-mindedness, push farther view, close look, take shift view, and combine six far away. One of the most widely used in landscape design is "step by step, single-minded, push far to see, combined with six far away".In order to meet the wishes of tourists, tracking down the trail of tourists, moving a foothold, as "scattered point perspective", so that the pace of the scene to, "step by step with the scene", attractive. Step by step to look at this "line" observation activities, but also to stop for a focus on a scene, carefully viewing, this is the "single-minded", the so-called "thousands of mountains are painted, only take a peak green." In the Chinese traditional garden design, emphasis on the natural landscape imitation of the garden (such as Suzhou garden) often "close at hand, write a thousand miles of view" of the aesthetic performance of the "push". However, the "splendid China" in Shenzhen is permeated with the aesthetic thought of "all facets", which condense the landscape with Chinese characteristics into a garden and form a "multi-faceted, leaping" composition mode. [6] Can be seen, an excellent garden design reflects the essence of the art of painting everywhere.

\section{Creation of artistic Conception}

Any art is not pure natural scenery imitation or reproduction, it must have the expression of human thoughts and feelings of nature, from the shaping of the form to the generation of the whole process of meaning, otherwise, it cannot be called art. The French realism school of painting preaches "to observe with the faith of the heart, then can hear the broad voice. "Instead of drawing the exact details of what we see, we represent the world we feel. " It is consistent with the view that Chinese painting advocates "both appearance and appearance, to form expression". Landscape and pastoral art formed to reproduce natural beauty and create nature, including landscape, landscape painting and pastoral poetry are embodied in the garden art. As far back as the Tang and Song dynasties, "freehand landscape garden" appeared in our country, in which the landscape was painted, the landscape was set up, and the scenery was mixed with each other. The "scene" in garden design should be poetic and picturesque, and only by applying the creative principle of "mind into the environment" advocated in painting in all aspects can we reach the goal of "looking at the mountains if not enough, always turning back step by step, and looking at the insufficient reciting of the water." The ethereal realm of "mental and things" in which water is driven from stream to stream. Left the artistic conception creation, the garden has lost the vitality, took the garden the plan designer. There's no difference between a florist and a gardener. To sum up, no matter in the plane of two-dimensional space, the body of three-dimensional space, the time of four-dimensional space, the meaning of five-dimensional space, or the collocation and harmony of colors, the principle of painting art has penetrated into all aspects of landscape design. In the process of modernization, as people have put the harmony with the natural environment in the first place, we should also put the beauty of painting and garden which originated from nature and life as a whole in our social life. So as to create ecological garden city, landscape city, garden city and other more suitable for the development of the natural environment of human settlements. 


\section{Acknowledgements}

Su Chang (1979.2 - ), female, Shenyang, Liaoning Province, master of literature, forestry college of Shenyang Agricultural University associate professor, department of landscape architecture, master tutor, the research direction is landscape planning and design, zip code: 110866.

\section{References}

[1] [2] Liu Yuan: "Aesthetic relationship between Landscape Design and painting" [J] Journal of Fuyang Teachers College (Social Science Edition) 1999 (2).

[3] Shen Shixian , Han Bingyue, Zhu Shaolin. Color and Modern Landscape. [J] planner 2006 (2).

[4] Wu Lieyan: "Research on specialized basic courses in the discipline of Art and Design" [D] Nanjing Institute of the Arts, Ph.D. 2001.

[5] Han Hong, Huang Xiaojin: a preliminary study of Landscape Architecture Art Teaching. [J] Forestry Education in China 2009 (1).

[6] Xiao Chunxia, Liu Xiu: reflections on Landscape Art Teaching [J] Journal of Liaoning Administrative College 2006 (1). 